\title{
Isolation and Characterization of Contaminant Mycoflora from Stored Red Peppers
}

\author{
R. Darsana ${ }^{1 *}$ (iD) and G. Chandrasehar ${ }^{2}$ (D) \\ ${ }^{1}$ Quality Evaluation Laboratory, Spices Board, Ministry of Commerce and Industry, Government of India, \\ Cochin - 682 025, Kerala, India. \\ ${ }^{2}$ International Institute of Biotechnology and Toxicology (IIBAT), Padappai - 601 301, Kancheepuram District, \\ Tamil Nadu, India.
}

\begin{abstract}
Red pepper is a spice vulnerable to fungal growth and mycotoxin contamination while in the field and postharvest during storage. Storage fungi are omnipresent and colonize fast when moisture levels go up, ultimately leading to mycotoxin production. Stored samples of the whole, crushed and ground red pepper in the Southern Indian States and Maharashtra, India were examined to isolate and characterize the prevalent contaminant fungal species. The average moisture content was below $10 \%$ for all the red pepper samples and the average total fungal load was less than $1 \times 10^{4} \mathrm{CFU} / \mathrm{g}$. Crushed red pepper showed higher fungal counts than ground and whole red pepper. The identified contaminant mycoflora belonged to the group; Aspergillus, Eurotium sp., Cladosporium sp., Eupenicillium sp., Penicillium sp., Miscellaneous fungi, Neosartorya sp., Curvularia sp., and Hyphopichia sp. Aflatoxigenic Aspergillus flavus was present only in $8.3 \%$ of the crushed and $2.54 \%$ of whole red pepper samples stored for more than two months.

Keywords: Red pepper, fungal contaminants, Aspergillus flavus, aflatoxin
\end{abstract}

*Correspondence: rajaputhrandarsana@gmail.com

(Received: May 01, 2021; accepted: June 06, 2021)

Citation: Darsana R, Chandrasehar G. Isolation and characterization of contaminant mycoflora from stored red peppers. J Pure Appl Microbiol. 2021;15(3):1187-1197. doi: 10.22207/JPAM.15.3.08

C The Author(s) 2021. Open Access. This article is distributed under the terms of the Creative Commons Attribution 4.0 International License which permits unrestricted use, sharing, distribution, and reproduction in any medium, provided you give appropriate credit to the original author(s) and the source, provide a link to the Creative Commons license, and indicate if changes were made. 


\section{INTRODUCTION}

Red pepper is an important tropical spice. The brilliant red colour, aroma and pungency of red pepper make it a desired adjunct in foods. The carotenoids and capsaicinoids are considered to be the most imperative chemical groups in red pepper. The chilli oleoresins have wide use ranging from food, drugs to cosmetics. Anti-oxidant and anti-cancerous activities have also been demonstrated for red peppers. ${ }^{1}$ Red pepper is therefore an important spice both in the international and domestic market ${ }^{2}$.

Red peppers are exposed to microbial contamination during pre and post-harvest. ${ }^{3}$ The storage fungi; Aspergillus sp. and Penicillium sp. are omnipresent and are the dominant species causing contamination in stored red peppers resulting in mycotoxin production ${ }^{4}$. Aflatoxin is the most studied among mycotoxins. Aflatoxin production has been reported in; A. flavus, $A$. parasiticus, A. nomius, A. pseudotamarii, A. bombycis, $A$. ochraceoroseus, and $A$. australis. A. flavus, known to have a worldwide distribution is an important and predominant fungus responsible for aflatoxin contamination in red peppers. Aflatoxicosis can be acute to chronic with mild to severe illness. Among aflatoxins, B1 is the most toxic and potent hepatocarcinogenic compound ${ }^{5}$.

Red peppers, among the spices, are more predisposed to contamination by mycotoxigenic species $^{6}$. The post-harvest practises such as drying, grading, packaging, transportation and storage are important factors as at each stage if proper care not taken, it would contribute to fungal proliferation and aflatoxin accumulation. The aim of the present study was to determine the fungal load in stored red peppers available in domestic markets of producing regions in the southern Indian states and Maharashtra, to identify the fungal contaminants and thereby evaluate the incidence of aflatoxigenic $A$. flavus.

\section{MATERIALS AND METHODS Collection of Samples}

Red pepper samples (whole red pepper $n=118$, crushed red pepper $n=24$ and ground red pepper $n=28$ ) stored in polythene bags and with a storage period greater than two months were collected from Kerala (KL), Karnataka (KR), Tamil Nadu (TN), Andhra Pradesh (AN), Telangana (TG) and Mumbai (MB). Samples of whole (W) red pepper $(n=128)$, crushed $(C)$ red pepper $(n=$ 43) and ground (Gr) red pepper $(n=51)$ with a storage time of less than two months were also collected from the areas. Sterile scissors, spatula, forceps and spoon (stainless steel) were used for collection. Samples were collected in sterile large plastic covers and plastic containers with proper seal. A 3-Class attribute plan was followed. A 375g incremental sample was collected from each bag. Minimum five such incremental samples collected from a lot were mixed together into a composite sample and the sample size was reduced by conning and quartering. The samples were stored at $4^{\circ} \mathrm{C}$ in the refrigerator until use and processed at the earliest possible maximum in a week's time.

\section{Moisture analysis}

Moisture determination in the red pepper samples was performed by azeotropic distillation. $25 \mathrm{~g}$ sample was transferred to distilling flask and sufficient volume of hexane was added to cover the sample completely and boiling chips were added. After assembling the apparatus, the trap was filled with hexane. A loose non-absorbing cotton plug was inserted into the top of the condenser, to prevent condensation of atmospheric moisture to the condenser. After bringing to boil, it was reflux at about two drops per second until most of the water was collected in the trap, then the reflux rate was increased to 4 drops per second. After two hours the reading was noted and refluxing continued until two consecutive readings 15 min apart showed no change so that the total extraction was 3 hours. Any water held up in the condenser was dislodged with a brush/wire loop. The condenser was carefully rinsed with $5 \mathrm{ml}$ hexane. The volume of water in the trap was read. The moisture content was reported to an accuracy of $0.0 \%$ (by weight) ${ }^{7}$.

Isolation and enumeration of total fungal colonies in the samples

Total fungal load was determined using the dilution plating method $^{8}$. $25 \mathrm{~g}$ sample was weighed into a sterile filter bag containing $225 \mathrm{ml}$ of sterile $0.1 \%$ peptone water. The filter bag containing the sample was homogenized in a stomacher for 2 minutes. The sterile filter bag formed the first dilution i.e., $10^{-1} .1 \mathrm{ml}$ from $10^{-1}$ dilution was transferred into a tube containing $9 \mathrm{ml}$ of sterile $0.1 \%$ peptone diluent. Likewise sample 
dilutions of up to $10^{-6}$ were prepared (Dilution rate; $1: 10=1+9) .1 \mathrm{ml}$ of the dilution was poured into pre-labelled sterile plates in triplicates. Dichloran $18 \%$ Glycerol agar (DG18) was immediately poured on to it. The poured plates were gently swirled clockwise and anti-clockwise. The plates were incubated upright in dark at $25^{\circ} \mathrm{C}$ for 5 days without disturbing. The plates were counted after five days of incubation. The plates were reincubated for another 48 hours if no growth was observed. Plates containing 10-150 colonies were counted. The results were expressed as Colony forming units per gram (CFU/g) based on average count of the triplicates.

Identification of fungal isolates and Qualitative detection of aflatoxigenic fungi

The fungal growth obtained from dilution plating method was carefully observed and sub-culturing of the selected fungi was done to obtain pure cultures. For identification of fungi, the isolates were grown on standard media. ${ }^{9}$ Lactophenol cotton blue staining was done for the fungal isolates and the microscopic features were noted. The colony colour, diameter and characteristics of seven day old culture on Czapek Yeast agar (CYA) at $25^{\circ} \mathrm{C}$, Glycerol $25 \%$ Nitrate (G25N) agar at $25^{\circ} \mathrm{C}, \mathrm{CYA}$ at $37^{\circ} \mathrm{C}$ and Czapek Yeast Agar with $20 \%$ sucrose (CY20S) incubated at $25^{\circ} \mathrm{C}$ were noted. The identification keys were used to identify the fungal isolate ${ }^{\text {. }}$.

Further all the fungal cultures were grown on Aspergillus differentiation medium (ADM) and thereafter inoculated into Coconut agar medium (CAM) for qualitatively detecting the aflatoxin producing capability of the isolates. For the preparation of coconut agar medium, $100 \mathrm{~g}$ of fresh shredded coconut was taken and mixed with $300 \mathrm{ml}$ of hot distilled water and homogenized using a blender for five minutes followed by filtration using cheesecloth (twolayered). $2 \mathrm{~N} \mathrm{NaOH}$ was used to adjust the $\mathrm{pH}$ of the medium to 7 . Agar at $1.5 \%$ was added and the media was autoclaved. ${ }^{10,11}$ The fungal colonies were single point inoculated into the Coconut agar plates and incubated for 5-7 days at 30ㄷ. Upon incubation, the plates were kept inverted and were examined under Ultra violet (UV) light at $365 \mathrm{~nm}$ in a dark room for fluorescence. Aflatoxin producing

Table 1. Total fungal load and moisture content of red peppers with more than two months storage

\begin{tabular}{lcccccc}
\hline \multirow{2}{*}{ Region } & \multicolumn{2}{c}{ Whole red pepper } & \multicolumn{2}{c}{ Crushed red pepper } & \multicolumn{2}{c}{ Ground red pepper } \\
& Moisture (\%) & CFUs/g & Moisture (\%) & CFUs/g & Moisture (\%) & CFUs/g \\
\hline KL & 9.6 & $1.1 \times 10^{3}$ & 8.1 & $4.2 \times 10^{3}$ & 8.0 & $2.7 \times 10^{3}$ \\
TN & 9.5 & $1.1 \times 10^{3}$ & 9.3 & $4.9 \times 10^{3}$ & 7.3 & $1.3 \times 10^{3}$ \\
KR & 8.4 & $6.5 \times 10^{2}$ & 9.5 & $4.3 \times 10^{3}$ & 6.3 & $8.5 \times 10^{2}$ \\
TG & 9 & $1.1 \times 10^{3}$ & 9.2 & $9 \times 10^{2}$ & 6.0 & $1 \times 10^{1}$ \\
AN & 9.5 & $1.1 \times 10^{3}$ & 7.1 & $3.9 \times 10^{2}$ & 6.4 & $8.8 \times 10^{2}$ \\
MB & 9.4 & $1.2 \times 10^{3}$ & 7.9 & $4.2 \times 10^{3}$ & 5.3 & $8.7 \times 10^{2}$ \\
\hline
\end{tabular}

KL - Kerala, TN - Tamil Nadu, KR - Karnataka, TG - Telangana, AN - Andhra Pradesh, MB - Mumbai

Table 2. Total fungal load and moisture content of red peppers with less than two months storage

\begin{tabular}{lcccccc}
\hline \multirow{2}{*}{ Region } & \multicolumn{2}{c}{ Whole red pepper } & \multicolumn{2}{c}{ Crushed red pepper } & \multicolumn{2}{c}{ Ground red pepper } \\
& Moisture (\%) & CFUs/g & Moisture (\%) & CFUs/g & Moisture (\%) & CFUs/g \\
\hline KL & 6.9 & $1.6 \times 10^{2}$ & 5.8 & $4.2 \times 10^{2}$ & 6.5 & $2.4 \times 10^{2}$ \\
TN & 6.5 & $2.1 \times 10^{2}$ & 6.5 & $3.8 \times 10^{2}$ & 4.0 & $1.9 \times 10^{2}$ \\
KR & 6.4 & $1.9 \times 10^{2}$ & 8.2 & $4.1 \times 10^{2}$ & 4.5 & $2.9 \times 10^{2}$ \\
TG & 8 & $2.4 \times 10^{2}$ & 8.2 & $3.1 \times 10^{2}$ & 3.8 & $1.0 \times 10^{1}$ \\
AN & 7.7 & $2.1 \times 10^{2}$ & 5.7 & $1.5 \times 10^{2}$ & 4.0 & $4.0 \times 10^{2}$ \\
MB & 6.5 & $2.4 \times 10^{2}$ & 5.8 & $3.8 \times 10^{2}$ & 4.7 & $2.2 \times 10^{2}$ \\
\hline
\end{tabular}

KL - Kerala, TN - Tamil Nadu, KR - Karnataka, TG - Telangana, AN - Andhra Pradesh, MB - Mumbai 
colonies showed fluorescence as bluish white/ white ring surrounding the colony. Uninoculated CAM plates were used as control'.

\section{RESULTS AND DISCUSSION}

In the present study, the average moisture content and total fungal load for whole, crushed and ground forms of red pepper samples with more than two months storage period were $9.2 \%, 8.5 \%, 6.6 \%$ and $1 \times 10^{3} \mathrm{CFU} / \mathrm{g}, 3.1 \times 10^{3}$ CFU/g, $1.1 \times 10^{3} \mathrm{CFU} / \mathrm{g}$, respectively (Table 1 ). Similarly, for samples with lower than two months storage, the average moisture content and total fungal load in whole, crushed and ground red pepper were $7 \%, 6.7 \%, 4.6 \%$ and $2.1 \times 10^{2} \mathrm{CFUs} / \mathrm{g}$, $3.4 \times 10^{2} \mathrm{CFU} / \mathrm{g}, 2.2 \times 10^{2} \mathrm{CFU} / \mathrm{g}$, respectively (Table 2). In a 3-Class attribute plan, the ' $m$ value' i.e., the microbiological limit if $\leq 1 \times 10^{4} \mathrm{CFU} / \mathrm{g}$ is considered satisfactory. The total fungal load in all the red pepper samples was less than $1 \times 10^{4}$ $\mathrm{CFU} / \mathrm{g}$. Thus the values were within the specified microbiological limits ${ }^{12}$.

Drying and storage of red pepper postharvest is considered critical because during these periods, the red peppers are not only subjected to changes in temperature and humidity but are also exposed to wind/dust, mechanical damage while handling and invasion by insects. Moisture content in red pepper is usually brought down to $13 \%$ during the drying stages in order to prevent fungal growth and its contamination. In the present study moisture content was found to be below $10 \%$ for all the red pepper samples. Despite the lower moisture content and the low water activity post drying, red peppers are still susceptible to fungal growth $^{6}$.

A total of 53 fungal isolates were identified from the red pepper samples: $K L-11$ isolates, TN -9 isolates, KR -9 isolates, TG -7 isolates, $\mathrm{AN}-4$ isolates and $\mathrm{MB}-13$ isolates (Figure 1). Majority of the isolates belonged to the genera Aspergillus, followed by Eurotium sp. (which is a teleomorph of Aspergillus sp. and formerly identified as the "Aspergillus glaucus group"), Cladosporium sp., Eupenicillium sp., Penicillium sp., Miscellaneous fungi, Neosartorya sp., Curvularia sp., and Hyphopichia sp (Figures 2 to 5).

Aspergillus tamarii was the fungal species prevalent in all the three forms of stored red pepper. It is a common occurrence in nuts and oil seeds. It has also been reported in spices $^{13}$. A. tamarii are not aflatoxin producers but produce another toxin called cyclopiazonic acid and the alkaloid fumiclavine $\mathrm{A}^{13}$. Eurotium sp. was also a common isolate from the red pepper samples. E. chevalieri produces toxic compounds called echinulin and neoechinulin that causes feed refusal in swine ${ }^{14}$. No mycotoxin production reported in E. repens ${ }^{9}$.

The other prevalent fungal isolates were from the Genera: Cladosporium and Eupenicillium. No mycotoxin production has been reported in $C$. herbarum and $C$. macrocarpum.

E. hirayamae are not mycotoxin producers whereas, E. ochrosalmoneum produces

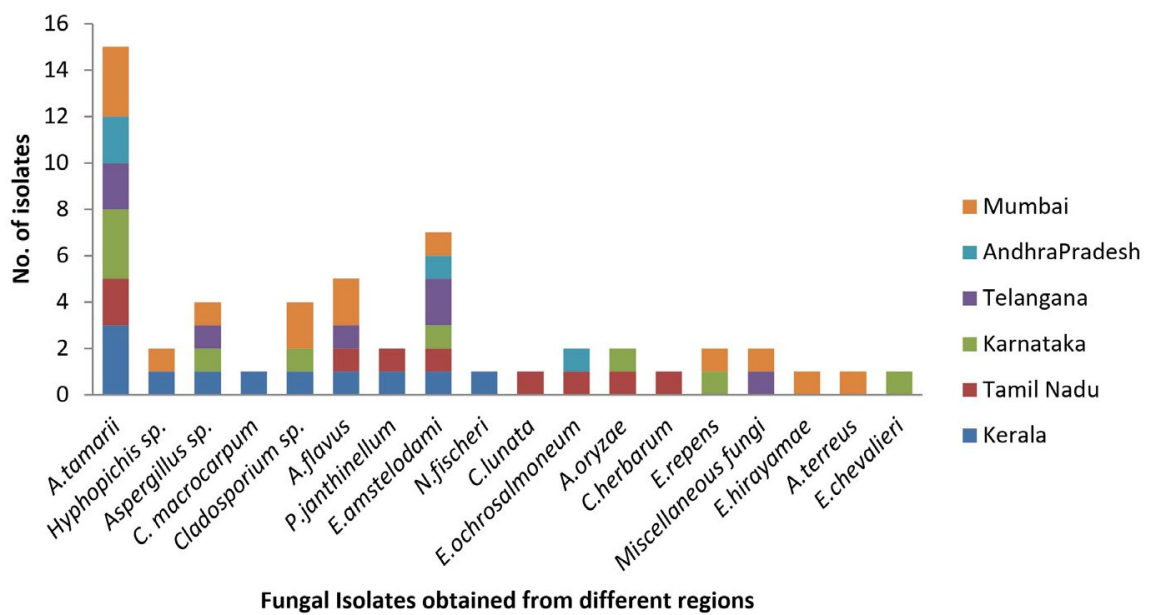

Fig. 1. Isolates of fungal genera from stored red peppers 


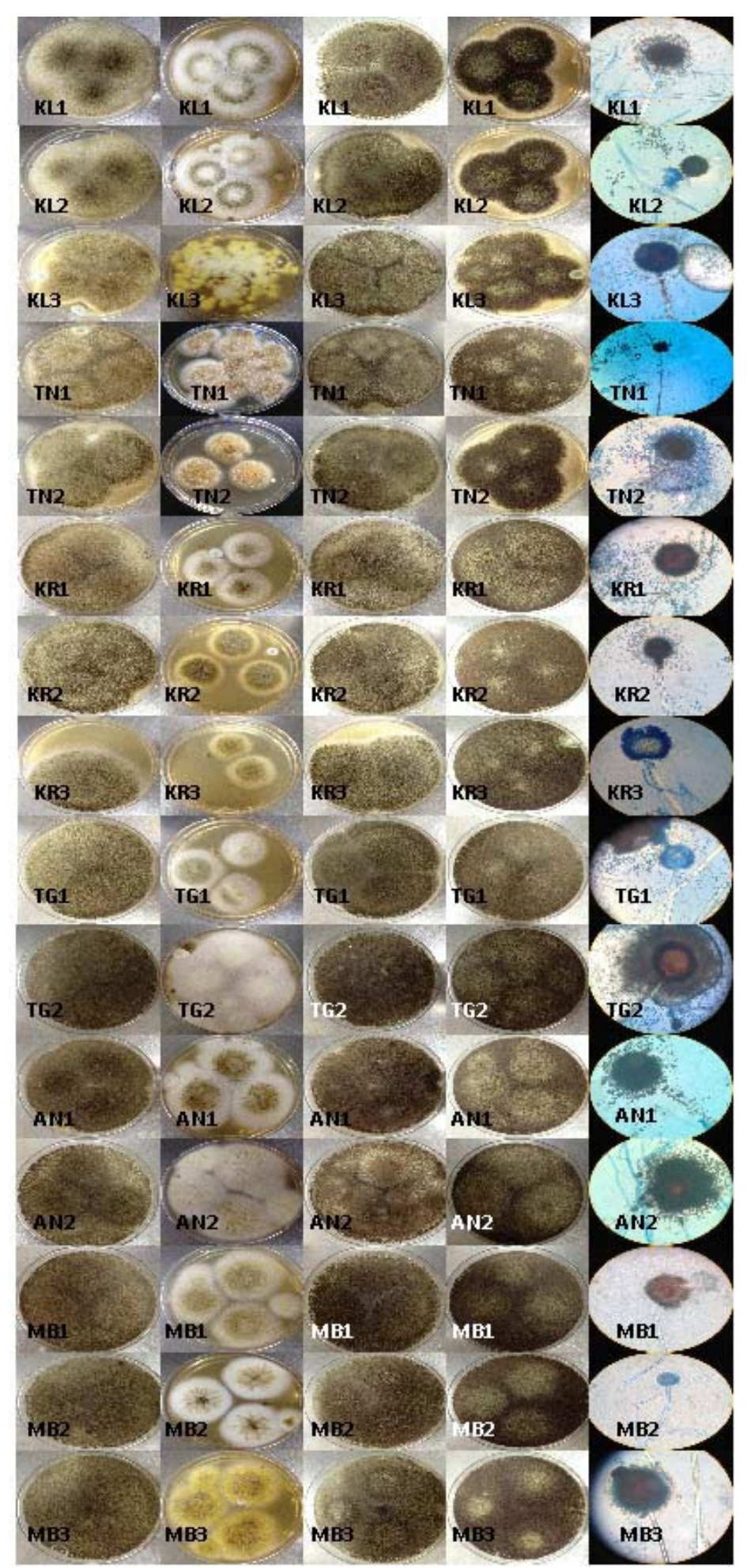

Fig. 2. Isolates of Aspergillus tamarii grown on CYA $25^{\circ} \mathrm{C}, \mathrm{G} 25 \mathrm{~N} 25^{\circ} \mathrm{C}, \mathrm{CYA} 37^{\circ} \mathrm{C}, \mathrm{CY} 20 \mathrm{~S} 25^{\circ} \mathrm{C}$ and microscopic view KL - Kerala, TN - Tamil Nadu, KR - Karnataka, TG - Telangana, AN - Andhra Pradesh, MB - Mumbai 


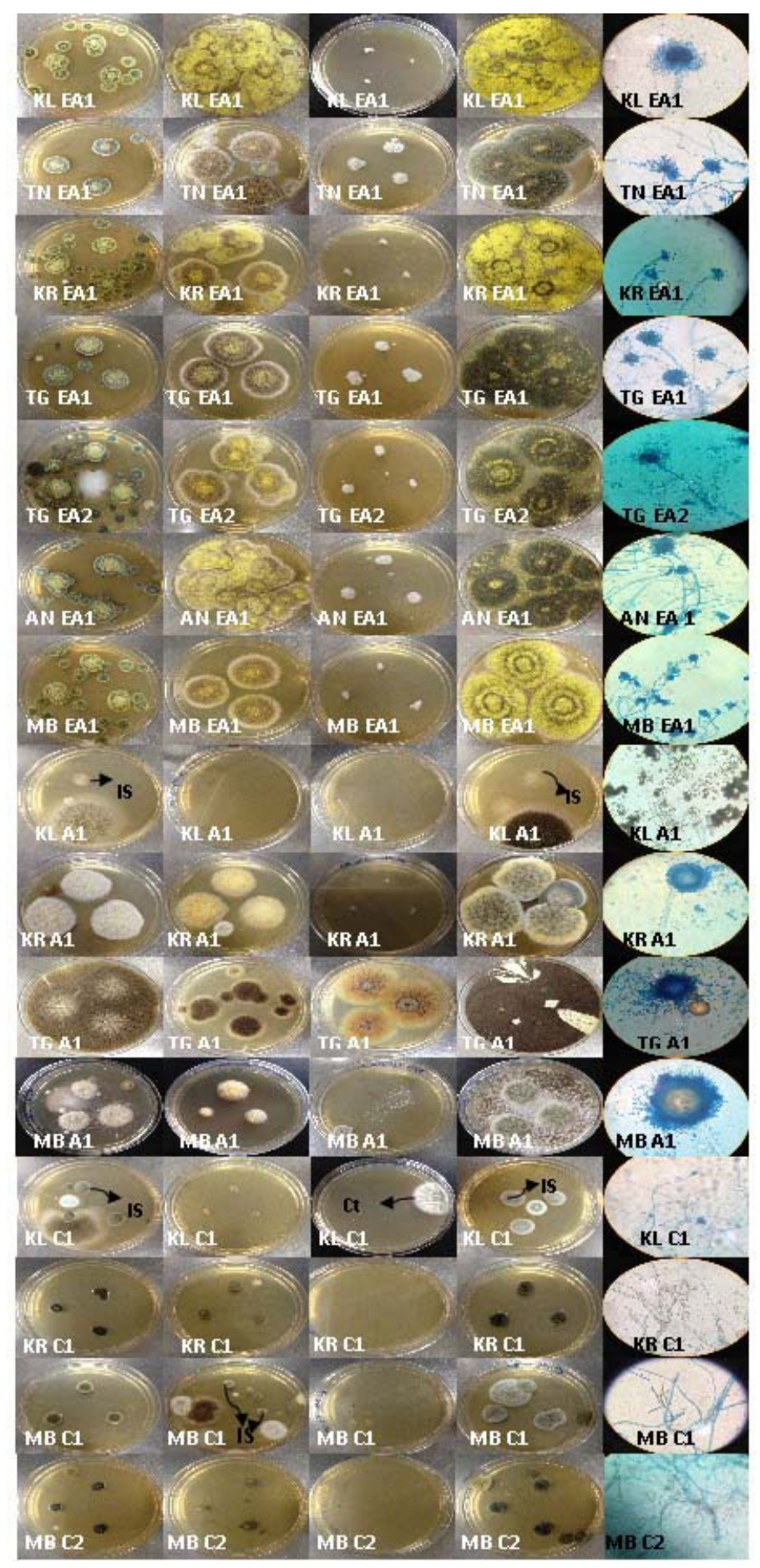

Fig. 3. Isolates of Eurotium amstelodami, Cladosporium sp., and Aspergillus sp., grown on $\mathrm{CYA} 25^{\circ} \mathrm{C}, \mathrm{G} 25 \mathrm{~N} 25^{\circ} \mathrm{C}$, $\mathrm{CYA} 37^{\circ} \mathrm{C}, \mathrm{CY} 20 \mathrm{~S} 25^{\circ} \mathrm{C}$ and microscopic view KL - Kerala, TN - Tamil Nadu, KR - Karnataka, TG - Telangana, AN - Andhra Pradesh, MB - Mumbai, EA - E. amstelodami, A - Aspergillus sp., C - Cladosporium sp., IS - Isolate, Ct - Contamination 


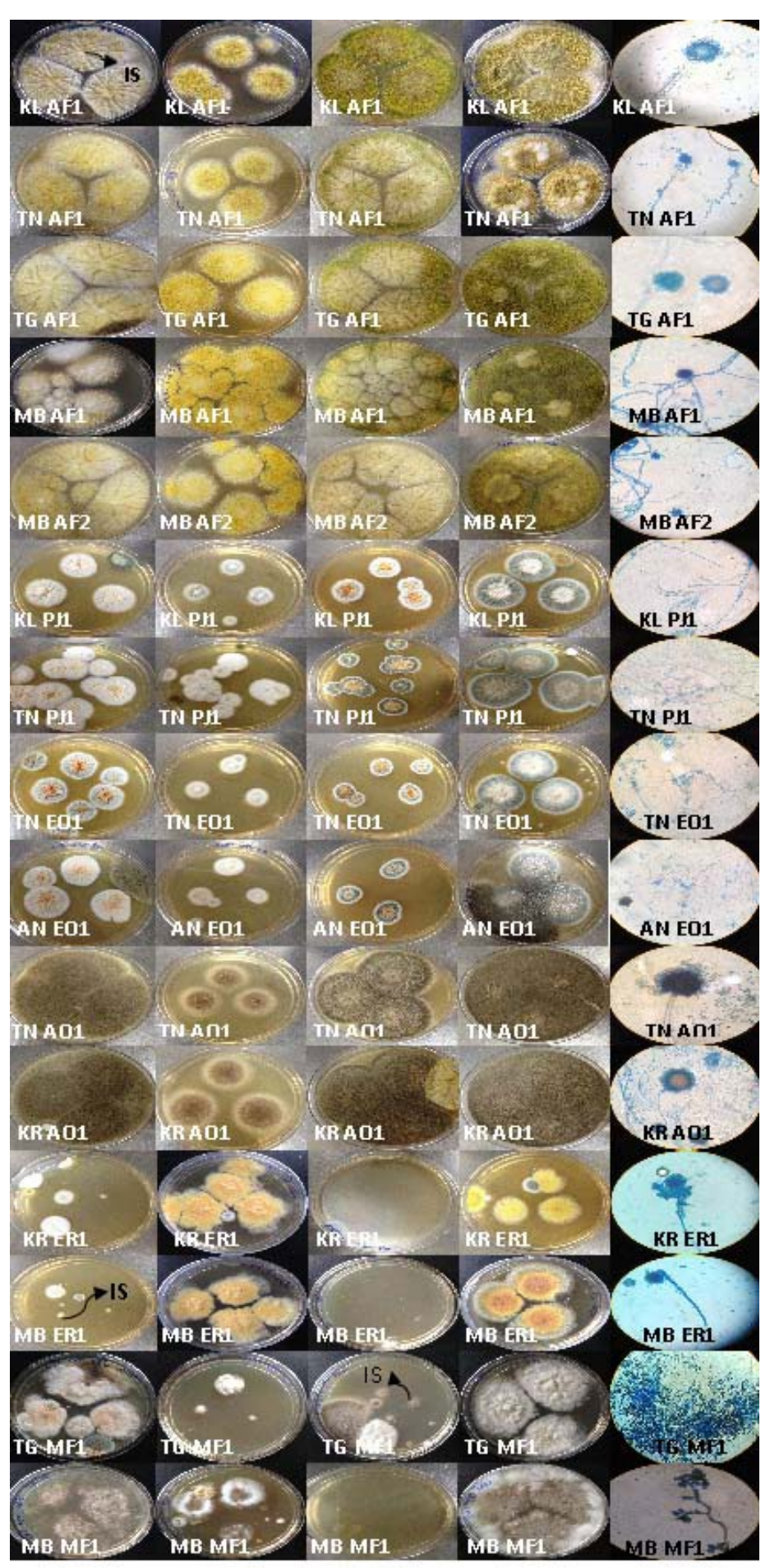

Fig. 4. Isolates of Aspergillus flavus, Penicillium janthinellum, Eupenicillium ochrosalmoneum, Aspergillus oryzae, Eurotium repens and Miscellaneous fungi grown on $\mathrm{CYA} 25^{\circ} \mathrm{C}, \mathrm{G} 25 \mathrm{~N} 25^{\circ} \mathrm{C}, \mathrm{CYA} 37^{\circ} \mathrm{C}, \mathrm{CY} 20 \mathrm{~S} 25^{\circ} \mathrm{C}$ and microscopic view $\mathrm{KL}$ - Kerala, TN - Tamil Nadu, KR - Karnataka, TG - Telangana, AN - Andhra Pradesh, MB - Mumbai, AF - A. flavus, $\mathrm{PJ}-$ P. janthinellum, EO-E. ochrosalmoneum, $\mathrm{AO}-\mathrm{A}$. oryzae, ER - E. repens and MF - Miscellaneous fungi, IS - Isolate 


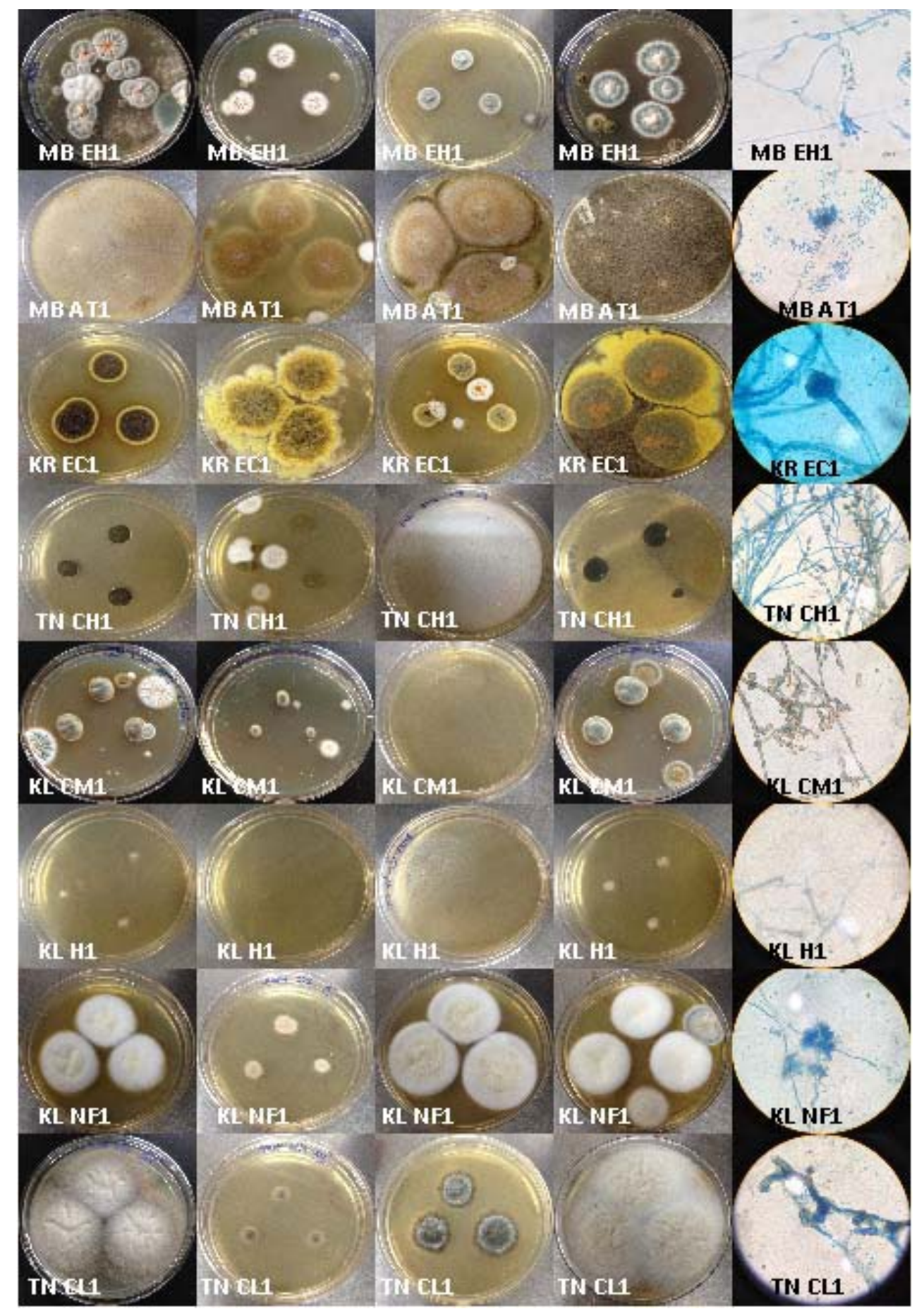

Fig. 5. Isolates of Eupenicillium hirayamae, Aspergillus terreus, Eurotium chevalieri, Cladosporium herbarum, Cladosporium macrocarpum, Hyphopichia sp., Neosartorya fischeri and Curvularia lunata grown on $\mathrm{CYA} 25^{\circ} \mathrm{C}$, $\mathrm{G} 25 \mathrm{~N} 25^{\circ} \mathrm{C}, \mathrm{CYA} 37^{\circ} \mathrm{C}, \mathrm{CY} 20 \mathrm{~S} 25^{\circ} \mathrm{C}$ and microscopic view.

$\mathrm{MB}$ - Mumbai, KR - Karnataka, TN - Tamil Nadu, KL - Kerala, EH - E. hirayamae, AT - A. terreus, EC - E. chevalieri, $\mathrm{CH}-\mathrm{C}$. herbarum, $\mathrm{CM}-\mathrm{C}$. macrocarpum, $\mathrm{H}-$ Hyphopichia sp., NF $-\mathrm{N}$. fischeri and $\mathrm{CL}-\mathrm{C}$. lunata 
a mycotoxin; citreoviridin in maize ${ }^{15}$. Some of the fungal isolates belonged to the genera Penicillium, Hyphopichia, Curvularia and Neosartorya. Penicillium janthinellum produces janthitrems; a series of tremorgenic toxins ${ }^{16}$. The genus Hyphopichia sp., which is a yeast-like fungi do not produce any mycotoxins ${ }^{9}$. In Curvularia sp., mycotoxin production has not been reported. Neosartorya produces fumitremorgens A and C and verruculogen ${ }^{17,18,19}$.
Most of the contaminant fungi isolated in the present study are a common occurrence in stored foods. Though some of them are mycotoxin producers, aflatoxin production is mainly seen among the species of Aspergillus genera. In the present study, five isolates of aflatoxigenic A. flavus were obtained from the samples. The characteristic orange colour in reverse of the ADM was indicative of $A$. flavus isolates (Figure 6),. All the other isolates showed uncoloured/pale reverse

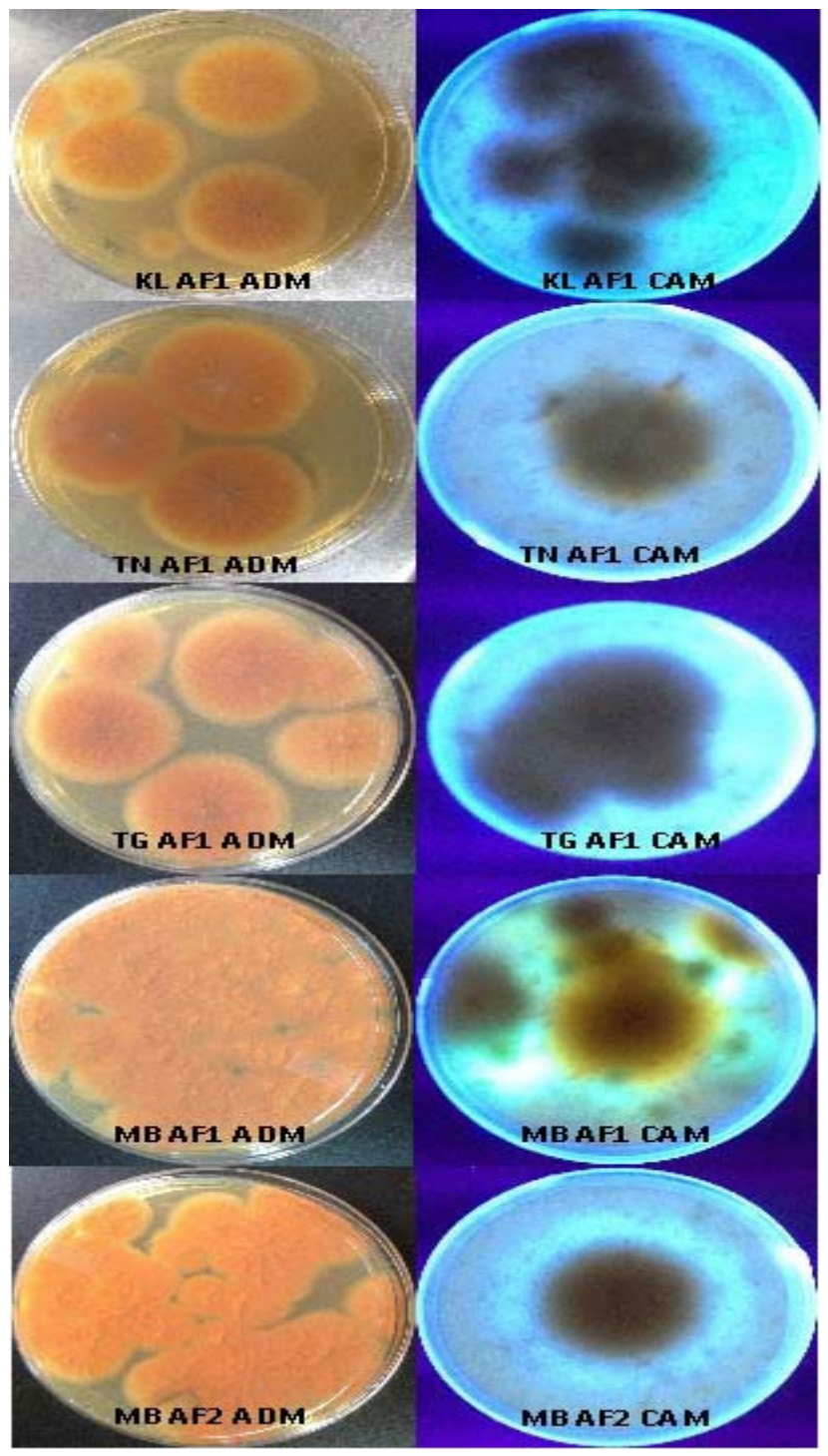

Fig. 6. Characteristic appearance of aflatoxigenic $A$. flavus on CAM and ADM $\mathrm{KL}$ - Kerala, TN - Tamil Nadu, TG - Telangana, MB - Mumbai, AF - A. flavus, ADM - Aspergillus differentiation medium, CAM - Coconut agar medium 
on ADM. Qualitative detection of aflatoxigenic $A$. flavus was done by growing the isolates on CAM. Aflatoxigenic $A$. flavus isolates grown on CAM, after incubation of five days showed a ring of blue fluorescence surrounding their colony growth when observed under UV light of $365 \mathrm{~nm}$ (Figure 6).

A. flavus is the main producer of aflatoxins; causing acute and chronic toxicity in animals and humans; acute liver damage, induction of tumours, teratogenic effect, liver cirrhosis, immunosuppression and interference with protein uptake. Chronic aflatoxin exposure also linked with impaired hepatic metabolism ${ }^{20,21}$. Importantly aflatoxin B1 has been classified as a group 1 carcinogen ${ }^{22}$.

In the present study, aflatoxigenic $A$. flavus was present only in $8.3 \%$ of crushed and $2.54 \%$ of whole red pepper samples stored for more than two months. $A$. flavus was not present in any of the other red pepper samples. Proper handling, packaging and storage conditions are essential factors during post-harvest of red peppers. With increase in storage time, the samples are being subjected to temperature/ humidity fluctuations due to the environmental conditions and the storage facilities maintained by suppliers of the respective regions. This could be the reason for incidence of $A$.flavus in a small percentage of samples stored for more than two months.

Red pepper is a spice used on a daily basis in all Indian households. In our country, red pepper is cultivated in the states of Andhra Pradesh, Gujarat, Karnataka, Maharashtra, Orissa, Rajasthan, Tamil Nadu, Telangana, Uttar Pradesh, West Bengal and Madhya Pradesh. India is not only the leading producer and exporter but also the leading consumer of red peppers ${ }^{23}$. The escalating international demands, the need for revenue build-up together with stringent regulations by the developed nations, could result in the best quality products being sold out of the country, and may leave behind a compromised lot that could enter the domestic market ${ }^{5}$. The people of the lower income group might be at risk by buying and consuming such red peppers. Continuously consuming toxin contaminated spice on a daily basis can have both acute and chronic impact on the health of the individual (young children, adult, immunocompromized individuals and nursing mothers). Considering the gastronomic use of red peppers in India, it would be of good reference if monitoring of red pepper in domestic markets of the major producing areas is done. This would aid in eventually generating a national database of information regarding the fungal load, the prevalent fungal contaminants and especially the incidence of aflatoxigenic A.flavus in the different regions and thus provide a rationale to strengthen the risk analysis procedures and ultimately ensure that good quality and safe red peppers are reaching the consumers.

\section{ACKNOWLEDGEMENTS}

We thank Ms. Srilatha C.M., (Scientist ' $C$ ' \& QELs' in-charge), Archana KP, Jisna KC and Sandya BK. (Trainee Analysts), Quality Evaluation Laboratory, Spices Board, Cochin, Kerala, India for editing the manuscript and for providing assistance on methods. We are also thankful to Dr. Ranjith Arimboor, Scientist C, Quality Evaluation Laboratory, Spices Board, Gummidipoondi, Chennai, Tamil Nadu, India for the valuable inputs in editing the manuscript.

\section{CONFLICT OF INTEREST}

The authors declare that there is no conflict of interest.

\section{AUTHORS' CONTRIBUTIONS}

Both the authors have made a substantial, direct and intellectual contribution to the work, and approved it for publication.

\section{FUNDING}

None

\section{DATA AVAILABILITY}

All datasets generated during this study are included in the manuscript.

\section{ETHICS STATEMENT}

This article does not contain any studies with human participants or animals performed by any of the authors.

\section{REFERENCES}

1. Zachariah TJ, P Gobinath. Chapter 14: Paprika and 
Chilli. In: Parthasarathy VA, Chempakam B, Zachariah TJ, Editors. Chemistry of Spices. UK: CAB International. 2008:260-286.

2. Peter KV, Editor. Handbook of Herbs and Spices. Volume 3. Cambridge, England: Woodhead Publishing Limited. 2006. ISBN: 978-1-84569-017-5.

3. Naik MK, Sudini HK. Aflatoxin contamination of food commodities and their management. In: Plant Pathology in India: Vision 2030. New Delhi: Indian Phytopathological Society; 2011:254-264. ISBN: 97881-8465-959-7.

4. Mandeel QA. Fungal Contamination of Some Imported Spices. Mycopathologia. 2005;159: 291-298. doi: 10.1007/s11046-004-5496-z.

5. Russell R, Paterson M. Aflatoxins contamination in chilli samples from Pakistan. Food Control. 2007; 18: 817-820. doi: 10.1016/j.foodcont.2006.04.005

6. Costa J, Rodríguez R, Garcia-Cela E, et al. Overview of Fungi and Mycotoxin Contamination in Capsicum Pepper and in Its Derivatives. Toxins. 2019; 11(1):27. doi: 10.3390/toxins 11010027

7. Astaspice. American Spice Trade Association. Moisture (Distillation Method), Method No.2.0, July 2011.

8. Total fungal count, United States Food and Drug Administration Bacteriological Analytical Manual, Chapter 18, Yeasts, Moulds and Mycotoxins, April 2001.

9. Pitt JI, Hocking AD. Fungi and Food Spoilage, Third edition. London (New York): Springer. 2009. doi: 10.1007/978-0-387-92207-2

10. Lin MT, JC Dianese. A Coconut-Agar Medium for Rapid Detection of Aflatoxin Production by Aspergillus spp. The American Phytopathological Society. 1976;14661469. doi: 10.1094/Phyto-66-1466

11. W Hammami, S Fiori, RA Thani, et al. Fungal and Aflatoxin Contamination of Marketed Spices. Food Control. 2014;37(1):177-181. doi: 10.1016/j. foodcont.2013.09.027

12. Food Safety and Standards Authority of India. Food Safety and Standards (Food Products Standards and Food Additives) Regulation, 2011. Microbiological Standards for Spices and Herbs, Amendment 70:2020.

13. Pitt JI, Hocking AD. Fungi and Food Spoilage, 2nd edn. London: Blackie Academic and Professional. 1997. doi: 10.1007/978-1-4615-6391-4
14. Vesonder RF, Lambert R, Wicklow DT, Biehl ML. Eurotium spp. and echinulin in feed refusal by swine. Appl Environ Microbiol. 1988; 54: 830-831. doi: 10.1128/aem.54.3.830-831.1988

15. Wicklow DT, Stubblefield RD, Horn BW, Shotwell OL. Citreoviridin levels in Eupenicillium ochrosalmoneuminfested maize kernels at harvest. Appl Environ Microbiol. 1988;54: 1096-1098. doi: 10.1128/ aem.54.5.1096-1098.1988

16. Gallagher RT, Latch GCM, Keogh RG. The janthitrems: fluorescent tremorgenic toxins produced by Penicillium janthinellum isolates from ryegrass pastures. Appl Environ Microbiol. 1980; 39: 272-273. doi: 10.1128/ aem.39.1.272-273.1980

17. Beuchat LR, Nielsen PV, Frisvad JC. Environmental factors influencing fumitremorgin production by Neosartorya fischeri : In Mycotoxins and Phycotoxins '88. Amsterdam; New York: Elsevier; 1989: 7-12.

18. Nielsen PV, Beuchat LR, Frisvad JC. Growth of and fumitremorgin production by Neosartorya fischeri as affected by temperature, light, and water activity. Appl Environ Microbiol. 1988; 54: 1504-1510. doi: 10.1128/ aem.54.6.1504-1510.1988

19. Frisvad JC, Samson RA. Mycotoxins produced by species of Penicillium and Aspergillus occurring in cereals. In Cereal Grain: Mycotoxins, Fungi and Quality in Drying and Storage, ed. J. Chelkowski. Amsterdam: Elsevier. 1991; 441-476.

20. Fuhrman MP, Charney P, Mueller CM. Hepatic proteins and nutrition assessment. J Am Diet Assoc. 2004; 104 : 1258-1264. doi: 10.1016/j.jada.2004.05.213

21. Muller $\mathrm{O}$, Krawinkel M. Malnutrition and health in developing countries. Can Med Assoc J. 2005; 173: 279-286. doi: 10.1503/cmaj.050342

22. IARC Monographs. A review of human carcinogens. Part F: Chemical Agents and related occupations / IARC Working Group on the Evaluation of Carcinogenic Risks to Humans. Lyon, France: International Agency for Research on Cancer; 2012.: 225-248.

23. Commodity, Definition of 'Red Chilli'. https:// economictimes.indiatimes.com/definition/Red-chilli. Accessed May 2, 2020. 